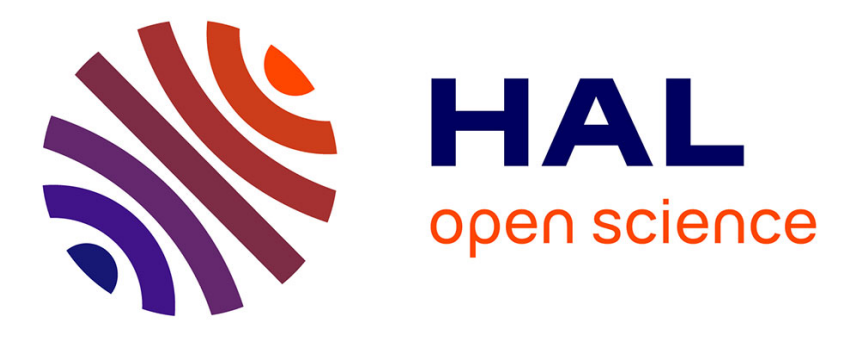

\title{
Use of calixarenes bearing diazonium groups for the development of robust monolayers with unique tailored properties
}

Ludovic Troian-Gautier, Alice Mattiuzzi, Olivia Reinaud, Corinne Lagrost, Ivan Jabin

\section{To cite this version:}

Ludovic Troian-Gautier, Alice Mattiuzzi, Olivia Reinaud, Corinne Lagrost, Ivan Jabin. Use of calixarenes bearing diazonium groups for the development of robust monolayers with unique tailored properties. Organic \& Biomolecular Chemistry, 2020, 18 (19), pp.3624-3637. 10.1039/d0ob00070a . hal-02533164

\section{HAL Id: hal-02533164 \\ https://hal-univ-rennes1.archives-ouvertes.fr/hal-02533164}

Submitted on 7 May 2020

HAL is a multi-disciplinary open access archive for the deposit and dissemination of scientific research documents, whether they are published or not. The documents may come from teaching and research institutions in France or abroad, or from public or private research centers.
L'archive ouverte pluridisciplinaire HAL, est destinée au dépôt et à la diffusion de documents scientifiques de niveau recherche, publiés ou non, émanant des établissements d'enseignement et de recherche français ou étrangers, des laboratoires publics ou privés. 


\section{Use of calixarenes bearing diazonium groups for the}

\section{development of robust monolayers with unique tailored}

\section{properties}

Ludovic Troian-Gautier, ${ }^{\dagger}$ Alice Mattiuzzi, ${ }^{\dagger, \perp}$ Olivia Reinaud, ${ }^{\&}$ Corinne Lagrost ${ }^{\mathfrak{*} *}$ and Ivan $\operatorname{Jabin}^{\dagger *}$

${ }^{\dagger}$ Laboratoire de Chimie Organique, Université libre de Bruxelles (ULB), CP 160/06, 50 avenue F.D. Roosevelt, 1050 Brussels, Belgium.

${ }^{\perp}$ X4C, 128 Rue du chêne Bonnet, 6110 Montigny-le-tilleul, Belgium

${ }^{\&}$ Laboratoire de Chimie et de Biochimie Pharmacologiques et Toxicologiques, CNRS UMR 8601, Université de Paris, 45 rue des Saints-Pères, 75006 Paris, France

${ }^{£}$ Université Rennes, CNRS, ISCR-UMR 6226, F-35000 Rennes (France)

Corresponding Authors corinne.lagrost@univ-rennes1.fr, ijabin@ulb.ac.be

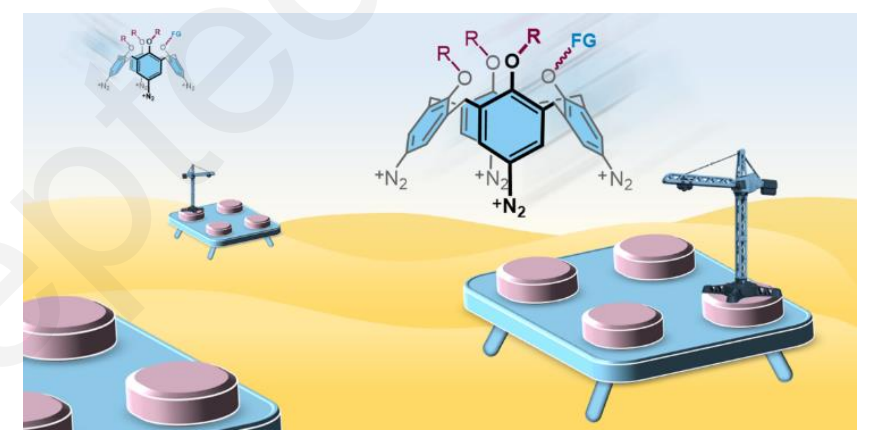

Calixarene-based diazonium salts can be easily synthesized in a few steps. This review surveys recent examples that illustrate the key advantages of these highly reactive molecular platforms for surface modification.

Abstract. Surface modification represents an active field of research that finds applications, amongst others, in the development of medical devices, sensors and biosensors, anti-biofouling materials, self-cleaning surfaces, surfaces with controlled wettability, corrosion resistance, 
heterogeneous catalysis and microelectronics. For some applications, surface functionalization with a nanometric-size monolayer is desired. In this review, efforts to covalently functionalize a wide array of surfaces with calixarenes bearing diazonium groups are described. More specifically, methodologies to obtain monolayers of calix[4 or 6]arene derivatives on conductive, semi-conductive or insulating surfaces as well as on nanoparticles are presented. The main advantages of this general surface modification strategy (i.e. formation of true monolayers that can be post-functionalized, high robustness and control over the composition of the calixarene-based coating) are discussed as well as its current scope of applications and future challenges.

\section{Introduction and Overview}

The surface chemistry of aryldiazonium salts has become a widely used tool for the preparation of modified surfaces since the pioneering work of Jean Pinson and his co-workers in $1992 .^{1}$ The increasing popularity of this methodology lies in the three following key points: i) the high robustness of the resulting interface due to the very strong attachment of the aryl moiety at the surface (adsorption energies over $50 \mathrm{kcal} / \mathrm{mol}$ ), ${ }^{2-4}$ ii) the compatibility of the method with a wide range of materials including conductive $(\mathrm{Au}, \mathrm{Ni}$, carbon in all forms, $\mathrm{Pt}$, $\mathrm{Cu}, \mathrm{Fe}, \mathrm{Zn}$, stainless steel, etc), semi-conductive ( $\mathrm{Si}, \mathrm{SiGe}, \mathrm{Ge}, \mathrm{GaAS}$, etc.), oxides (ITO, $\mathrm{TiO}_{2}$, $\mathrm{SnO}_{2}, \mathrm{SiO}_{2}$, etc), and even insulating (glass, PMMA, PET, PP, etc.) substrates, being either massive, flat surfaces or nanomaterials, ${ }^{5,6}$ and iii) the high diversity of diazonium salts that can be used (para-substituted aryl derivatives, ${ }^{4,5}$ porphyrins, ${ }^{7-10}$ calixarenes, ${ }^{11-20}$ pyridine, ${ }^{21,}{ }^{22}$ polyoxometalates,${ }^{23}$ transition metal complexes, ${ }^{24-27}$ biomolecules, ${ }^{28-30}$ etc). The grafting of diazonium salts has raised academic interest in various fields such as sensing, catalysis, anticorrosion, anti(bio-)fouling, molecular electronics. ${ }^{5}$ It has also led to industrial applications of innovative materials like modified carbon blacks and drug-eluting stents. ${ }^{31}$ The grafting 
could be activated by employing various techniques or routes, namely electrochemistry (cyclic voltammetry (CV), chronoamperometry, scanning electrochemical microscopy (SECM)), reduction by chemical agents, photochemistry, ultrasonication, neutral or basic $\mathrm{pH}$, heating and microwave. ${ }^{32}$ Most common media are aprotic organic solvents (acetonitrile, DMF) and aqueous acidic solutions. Several mechanisms have been proposed to explain the film formation, depending on substrates, diazonium derivatives and/or grafting medium. ${ }^{32}$ It is generally admitted that the grafting process starts by the concerted formation of an aryl radical upon reduction, which is capable to bind to the surface. Because of the high reactivity of these produced aryl radicals, loosely packed multilayers are generally formed with thickness typically in the range 10-15 $\mathrm{nm}$. The radicals can either react with the surface of the material or with already grafted moieties. A second pathway is also possible where the already grafted moiety reacts with an aryldiazonium cation, forming azo linkages that have been experimentally observed on several occasions. ${ }^{5}$ It is rather challenging with diazonium chemistry to exert a molecular control of the vertical extension as well as of the layer morphology. ${ }^{33,}{ }^{34}$ These aspects may be of critical importance for developing some applications, i.e. electrochemical sensors or electrocatalysis. Both of these applications require fast (electronic) communication between the sensitive layer and the analyte or compound to activate. In addition, having a thin layer, and especially a monolayer, allows the design of well-defined functional structures. Starting from a monolayer, further controlled post-functionalization through chemical couplings is possible in order to build well-organized functional interfaces for a dedicated application. From an experimental point of view, (true) monolayers formation is still delicate to evidence since thickness, compactness and surface concentrations of the film should be considered altogether.

During the last decade, many efforts have been made to develop strategies for preparing monolayers. ${ }^{33-35}$ One of them relies on the strict control of experimental conditions, such as the 
concentration of diazonium precursors or the electrolysis time, but it generally leads to sparse sub-monolayers with poor reproducibility. Sterically-hindered aryldiazonium salts have been shown to form monolayers. ${ }^{36-43}$ Interestingly, bulky protecting groups could be removed, leaving a monolayer with chemically-reactive terminal groups for further postfunctionalization. ${ }^{38-43}$ Viscous ionic liquids were also successfully employed to form thin films or, even monolayers. ${ }^{44-47}$ A radical scavenger was added to the grafting medium in order to limit the film growth and, thus, near-monolayers could then be produced with a relative simplicity. ${ }^{48-50}$ The authors first put forward a mechanism based on a radical trapping: it consists in a radical coupling between the aryl radical produced upon reduction of diazonium cations and the radical scavenger. In a more recent work, they actually demonstrated that the radical scavenger is more likely acting as a redox mediator than a radical trapping species. ${ }^{51}$ Lastly, strategies that take benefit of pre-organized rigid structures have been smartly exploited for preparing monolayers. ${ }^{11-20,26,52,53}$ Especially, in this connection, we have recently developed an innovative strategy based on the direct grafting of calix[4]arene diazonium salts constrained in the cone conformation. ${ }^{12,14-20}$

Densely packed monolayers were obtained through the reduction of calix[4]arene-based diazonium cations. Calix[4]arenes are macrocyclic molecules made up of four aromatic subunits linked through methylene bridges. ${ }^{54}$ The large rim of the calix[4]arenes is functionalized with one or four diazonium functions while the small rim could support reactive termini for subsequent post-functionalization. Such compounds could be easily synthetized at the gram-scale. Due to their structure, cone-constrained calix[4]arenes are particularly interesting molecular platforms for diazonium surface grafting: i) the methylene bridge prevents side reactions from the aryl radical and thus the formation of multilayers ii) appending arms at the small rim allow the introduction of various functional molecules or objects with a fine spatial control imposed by the small rim geometry and iii) several diazonium functions at the 
large rim provide multiple anchoring points, which is expected to enhance the stability of the monolayer. Indeed, in the case of self-assembled monolayers, it has been shown that multidentate anchors could be beneficial to the stability and the organization of the layer. ${ }^{55}$

Here, the recent advances of the use of calixarenes diazonium derivatives for the formation of robust and compact monolayers are presented. Common synthetic routes to these derivatives are first described, followed by their use for surface modification of conductive, semi-conductive and insulating surfaces as well as nanoparticles. Experimental evidences showing the formation of compact, robust and post-functionalizable monolayer of controlled composition are presented. Finally, the use of these tailored surfaces for applications such as anti-biofouling, chemical sensing in water and the development of hydrophobic surfaces are discussed.

\section{Synthesis and characterization of calix[n]arenes bearing diazonium groups}

Calix[n]arenes are oligomeric macrocycles composed of " $n$ " para-substituted phenolic units linked in the ortho position through methylene bridges. ${ }^{54}$ Many oligomers have been reported but those with $n=4,6$ or 8 are the most common. Calix[n]arene derivatives are more flexible than other macrocyclic compounds such as resorcinarenes, cyclodextrins and cyclotriveratrylenes, which lead to several remarkable conformations in solution. ${ }^{56}$ The socalled cone conformation displays a small rim composed of phenolic units and a larger rim composed of the para-substituted groups (Figure 1).

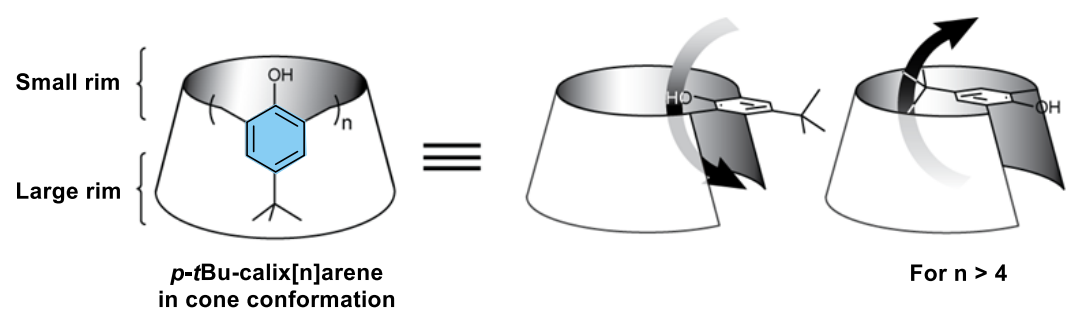

Figure 1. Schematic representation of a calix[n]arene macrocycle in cone conformation and the possible annular rotations. 
The cone conformation is desired for most of the applications and in particular for surface grafting with controlled geometry. In order to lock calix[4]arenes in this conformation and avoid the through annular rotation, the phenol moieties must be substituted by groups larger than an ethyl chain. For calix[6]arenes, rotation though the annulus of the para substituents is feasible, which makes the rigidification of the whole structure more challenging. Strategies such as capping of the small rim can be achieved to conformationally lock calix[6]arenes into the cone conformation. ${ }^{57}$ Calix[4 and 6]arenes that have been used so far for surface modification through the diazonium methodology are represented in Figure 2.

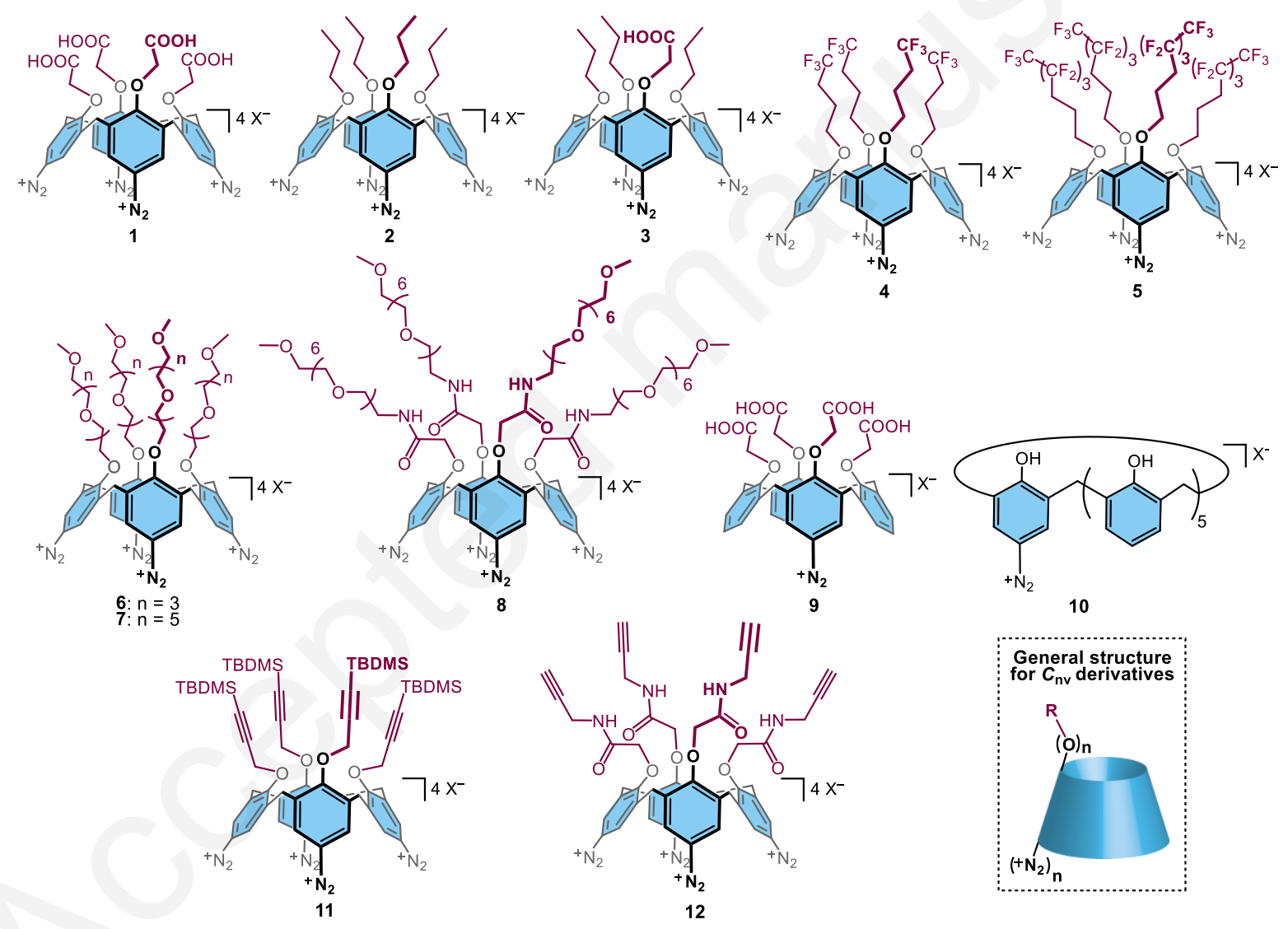

Figure 2. Structures of calix[4 or 6]arenes derivatives 1-12 discussed in the present work. Inset: general structure of $C_{\mathrm{nv}}$ symmetrical calix[n]arenes bearing diazonium groups. ${ }^{11-20}$

$C_{4 \mathrm{v}}$ or Cs symmetrical calix[4]arene tetradiazonium salts 1-8 and 11-12 have been prepared through classical routes that involve common synthetic steps: i) a tetraalkylation of the phenol units, ii) an ipso-nitration reaction, iii) a reduction of the resulting nitro groups into the 
corresponding amines, and finally iv) a diazotization reaction (for a representative example, see Figure 3 for the synthesis of the $C_{4 \mathrm{v}}$ symmetrical calixarene 4).

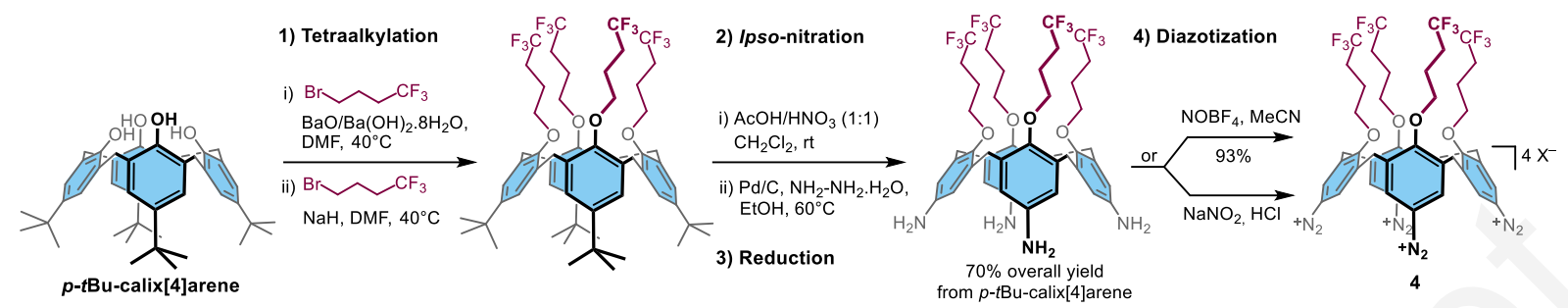

Figure 3. Scheme for the synthesis of calix[4]arene 4.

For the monodiazonium derivative $\mathbf{9}$, a seven-step synthetic route was developed following i) a trisalkylation of the phenol units, ii) para bromination of the unsubstituted phenol, iii) alkylation of the remaining phenol unit, iv) bromo- to azido- exchange through a coppercatalyzed reaction, v) hydrolysis of the ester functions, vi) Staudinger reduction of the azido group to the corresponding amine and finally vii) a diazotization reaction (Figure 4, top). ${ }^{15}$ Compound $\mathbf{1 0}$ was obtained in five steps that involved: i) protection of five phenol units out of the six using benzyl chloride, ii) para nitration of the unsubstituted phenol, iii) deprotection with sodium hydroxide, iv) reduction of the nitro group using hydrazinium monoformate and zinc dust and finally v) a diazotization reaction (Figure 4, bottom). ${ }^{11}$ 


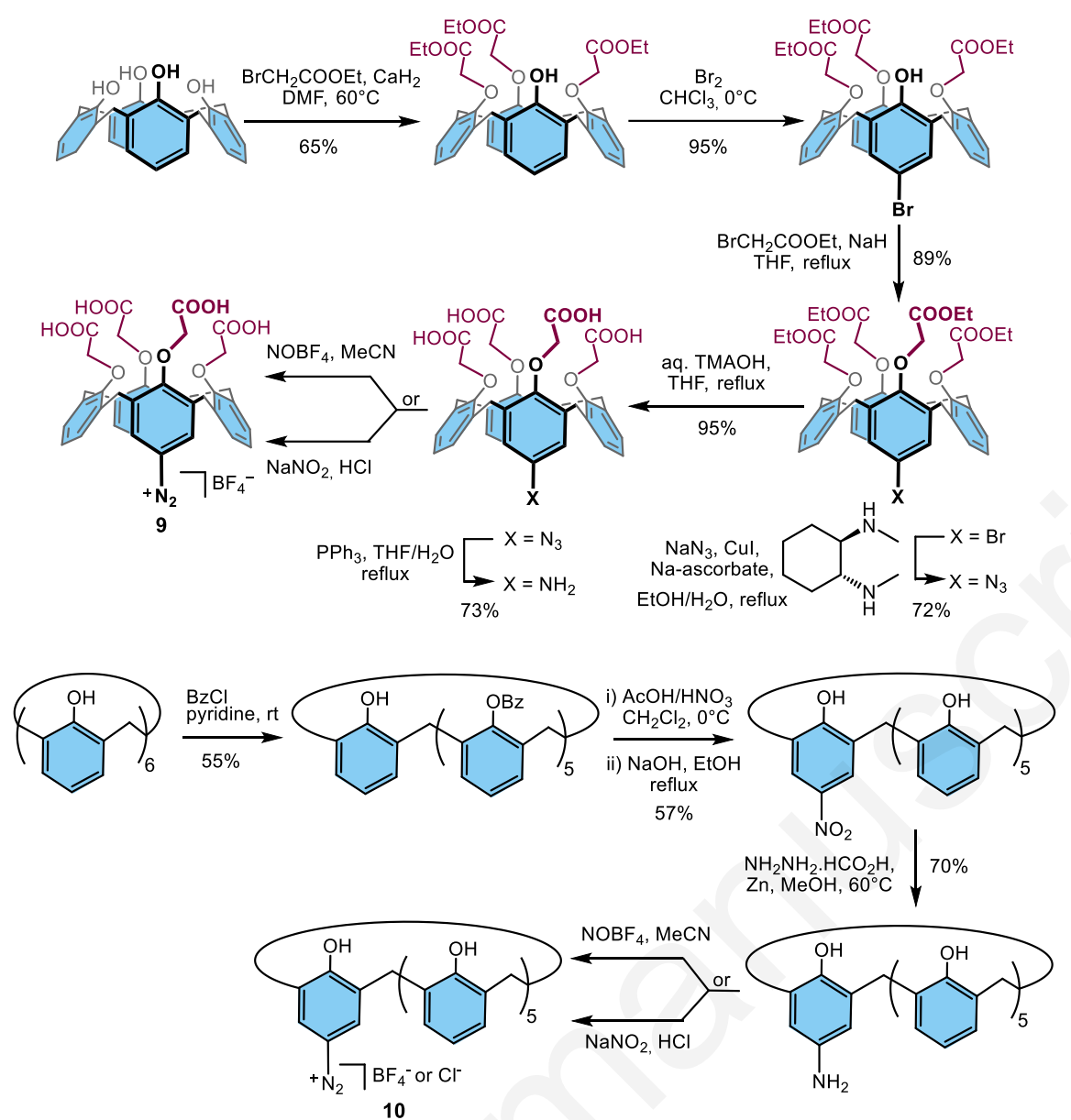

Figure 4. Synthetic routes for calix[4]arenes 9 (top) and $\mathbf{1 0}$ (bottom).

Calix[4]arene diazonium derivatives are easily characterized by common techniques including ${ }^{1} \mathrm{H}$ NMR and infrared spectroscopy. Indeed, the diazonium group has a unique signature in infrared spectroscopy with an intense signal around $2260 \mathrm{~cm}^{-1} \cdot{ }^{1} \mathrm{H}$ NMR spectroscopy is also very informative regarding the structure and symmetry of the different derivatives. As a representative example, the ${ }^{1} \mathrm{H}$ NMR spectrum of calix[4]arene tetradiazonium 4 is shown in Figure 5. This $C_{4 \mathrm{v}}$ symmetrical compound exhibit one doublet for the $\mathrm{ArCH}_{a x}$ protons, one doublet for the $\mathrm{ArCH}_{e q}$ protons, and one triplet for the eight $\mathrm{CH}_{2} \mathrm{O}$ protons. Additionally, a singlet for the eight $\mathrm{ArH}$ aromatic protons is observed. This peak is often deshielded compared to the amine precursor, consistent with the introduction of electron withdrawing $\mathrm{N}_{2}{ }^{+}$groups. Interestingly, compounds $\mathbf{1 - 9}$ have been stored in the fridge for several months without any sign of degradation. This stability was also demonstrated by 
thermogravimetric analysis (TGA) of compound $\mathbf{4}$, which showed that decomposition of this compound occurs at temperature greater than $120^{\circ} \mathrm{C}$ (Inset Figure 5). ${ }^{58}$

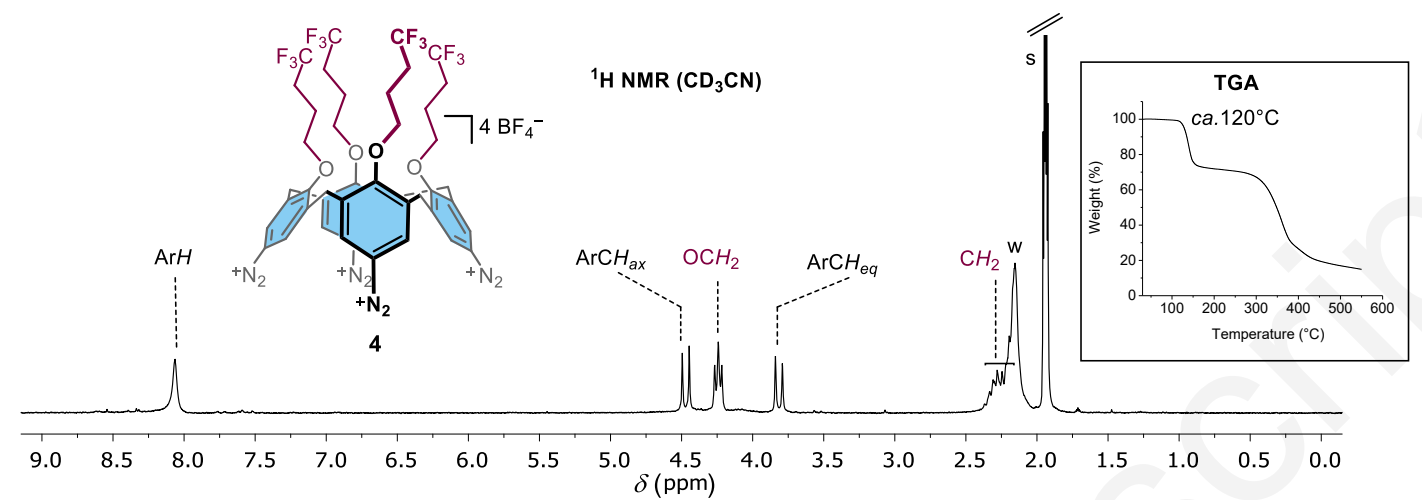

Figure 5: ${ }^{1} \mathrm{H}$ NMR $\left(\mathrm{CD}_{3} \mathrm{CN}, 300 \mathrm{MHz}\right)$ spectrum of $C_{4 \mathrm{v}}$ symmetrical calix[4]arene tetradiazonium 4. Inset: thermogravimetric analysis of $\mathbf{4}^{58}$

3. A versatile grafting methodology: modification of conductive, semi-conductive and insulating surfaces as well as nanoparticles

Calixarenes bearing diazonium groups could be efficiently grafted on a plethora of surfaces that include conductors, semi-conductors, insulators as well as nanoparticles (NPs). The common approach for this polyvalent grafting stems from the formation of reactive radicals that can be produced either chemically or electrochemically in the case of conductive surfaces (Figure 6).

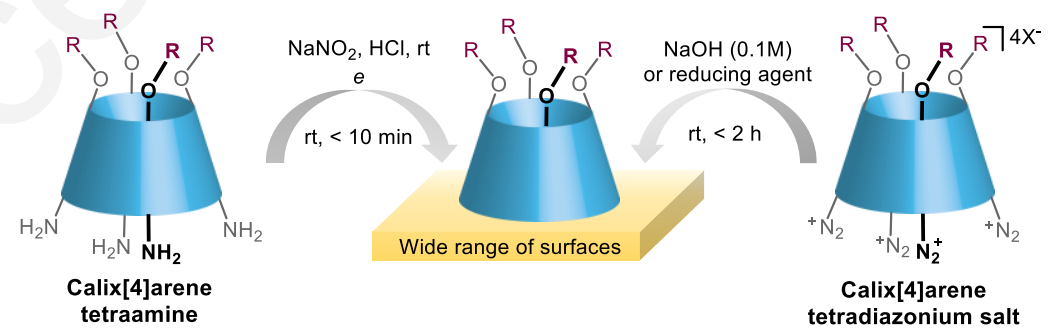

Figure 6. General strategies for the grafting of calix[4]arene tetradiazonium salts or their corresponding tetraamino precursors. 
Two techniques have been used for the electrochemical grafting of diazonium derivatives. The first one involves cyclic voltammetry, where a potential is cycled in a range including the diazonium's reduction potential ( $c a .-0.25 \mathrm{~V}$ versus SCE). The second one uses chronoamperometry where a constant potential (typically $-0.5 \mathrm{~V}$ versus SCE), more negative than the diazonium's reduction potential, is applied for a specific time. Reactive radicals are then produced close to the electrode surface and quickly lead to surface modifications. Electrochemical grafting of calix[4]arene tetradiazonium salts $\mathbf{1 - 4}$ has been successfully applied to different conductive surfaces, namely gold, pyrolyzed photoresist films (PPF), and glassy carbon. The monodiazonium salts $\mathbf{9}$ and $\mathbf{1 0}$ have also been used to modify glassy carbon electrodes. ${ }^{11,15}$ The charge transfer blocking properties of the calix[4]arene-coated electrodes were evaluated in aqueous solutions using redox probes such as potassium ferricyanide $\left(\mathrm{K}_{3} \mathrm{Fe}(\mathrm{CN})_{6}\right)$ or dopamine (Figure 7). ${ }^{59}$ The grafted monolayer of calix[4]arene acts as a barrier that considerably slows down the electron transfer kinetics of these two redox probes, provided that the formed layer is enough compact and homogeneous. The blocking properties of the layer of calix[4]arenes is evidenced by a larger peak-to-peak separation along with a dramatic decrease of the current intensity for the two selected redox probes. Furthermore, dopamine oxidation to the corresponding quinone in acidic medium is a surface-bound phenomenon requiring the adsorption of dopamine at the electrode. The electrochemical measurements of dopamine oxidation are hence strongly sensitive to the presence of pinholes or defects within the grafted layer, hence being a remarkable tool for probing the compactness of the layer. 

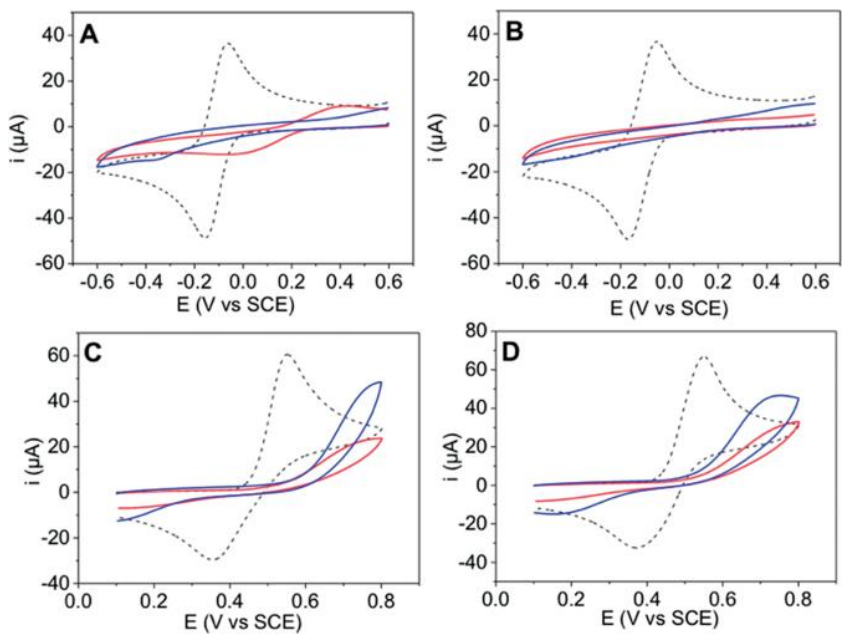

Figure 7. Cyclic voltammetry at glassy carbon electrodes of $1 \mathrm{mM}$ potassium ferricyanide in aqueous $0.1 \mathrm{M} \mathrm{KCl}$ (A-B) and of $2 \mathrm{mM}$ dopamine in aqueous $0.1 \mathrm{M} \mathrm{H}_{2} \mathrm{SO}_{4}(\mathrm{C}-\mathrm{D})$ before (dashed lines) and after (solid lines) electrografting of calix[4]arenes 1 (blue) and 9 (red) through cyclic voltammetry (A, C) or through chronoamperometry (B, D). Scan rate is $0.2 \mathrm{~V} \mathrm{~s}^{-1}$. Reproduced with permission from reference [15]. Copyright 2018 John Wiley and Sons.

The covalent grafting of calix[4]arene derivatives was also developed on conductive, semi-conductive and insulating surfaces, as well as on nanoparticles. Typical procedures involve the use of a chemical reductant such as $\mathrm{NaBH}_{4}$ or the formation of diazoate intermediates using sodium hydroxide. Note that it is known in the literature that the grafting of classical aryl diazonium derivatives can be also initiated by sulfuric acid, phosphoric acid or other reducing agents, such as elemental iron or zinc powder. ${ }^{60}$ The formation of diazoates was used to covalently immobilize calix[4]arenes $\mathbf{1}$ and $\mathbf{4}$ onto gold, polypropylene, polyethylene terephthalate and polystyrene materials. ${ }^{18}$ Calix[4]arene 5 was used in an analogous way to modify glass, gold and polypropylene surfaces. ${ }^{61}$ Similar grafting strategies have yielded germanium surfaces modified with calix[4]arenes 6 and 7. ${ }^{12} \mathrm{NaBH}_{4}$ was also used as reducing agent for the synthesis of calix[4]arene-coated gold nanoparticles (AuNPs-calix), either formed in situ from gold precursors (one-step) or through ligand exchange of citrate capped AuNPs. ${ }^{19}$, 20

Characterization techniques, such as X-Ray photoelectron spectroscopy (XPS), atomic force microscopy (AFM), ellipsometry or infrared absorption spectroscopy, were used to 
further assess the grafting of calixarene derivatives on conductors, semi-conductors, insulators and nanoparticles. ${ }^{12,13,16-20}$ For XPS analyses, the introduction of a chemical tag such as $\mathrm{CF}_{3}$ substituents on the calixarene rim was very effective since carbon, nitrogen and oxygen are not only common constituents of calixarene backbones, but are also common organic impurities and surface contaminants. In addition to the fluorine photoelectron F1s signal at $688 \pm 1 \mathrm{eV}$, $\mathrm{CF}_{3}$ has a specific contribution in the core level spectrum of carbon $\mathrm{C} 1 \mathrm{~s}$ at $293 \pm 0.5 \mathrm{eV}$. The grafting of calix[4]arenes $\mathbf{4}$ and $\mathbf{5}$ was evidenced this way on insulating surfaces such as polypropylene, polyethylene terephthalate, polystyrene and glass. ${ }^{18,61}$

\section{Formation of "true" monolayers}

As inferred in the introductive section, the formation of a true monolayer is not straightforward to demonstrate. Apart compactness, thickness of the layer is obviously the first key point to determine, and atomic force microscopy (AFM) or ellipsometry (on reflective surfaces) are usually employed. Thickness evaluation with AFM is based on the so-called “scratching” methodology, employing surfaces with very smooth surface roughness (e.g. PPF). The AFM tip is used to scratch away a section of the layer and then profiling across the scratch. ${ }^{62}$. Topography analysis was performed on gold, germanium, PPF and polypropylene surfaces coated with calix[4]arenes 1 and 4-7 (Figure 8), showing the formation of very homogeneous layers onto these substrates. Scratching experiments on PPF, germanium or gold

surfaces demonstrated the formation of monolayers of calix[4]arenes. ${ }^{12,16,18}$ For instance, a thickness of $1.3 \pm 0.1 \mathrm{~nm}$ was measured for calix[4]arene 4 on gold by scratching experiments and this result was further supported by ellipsometry measurements with a value of $1.09 \pm 0.2$ nm. ${ }^{16}$ These results agreed well with the $1.1 \mathrm{~nm}$ height estimated from MM2 energy minimizations and hence confirmed the formation of a monolayer on gold surfaces. 

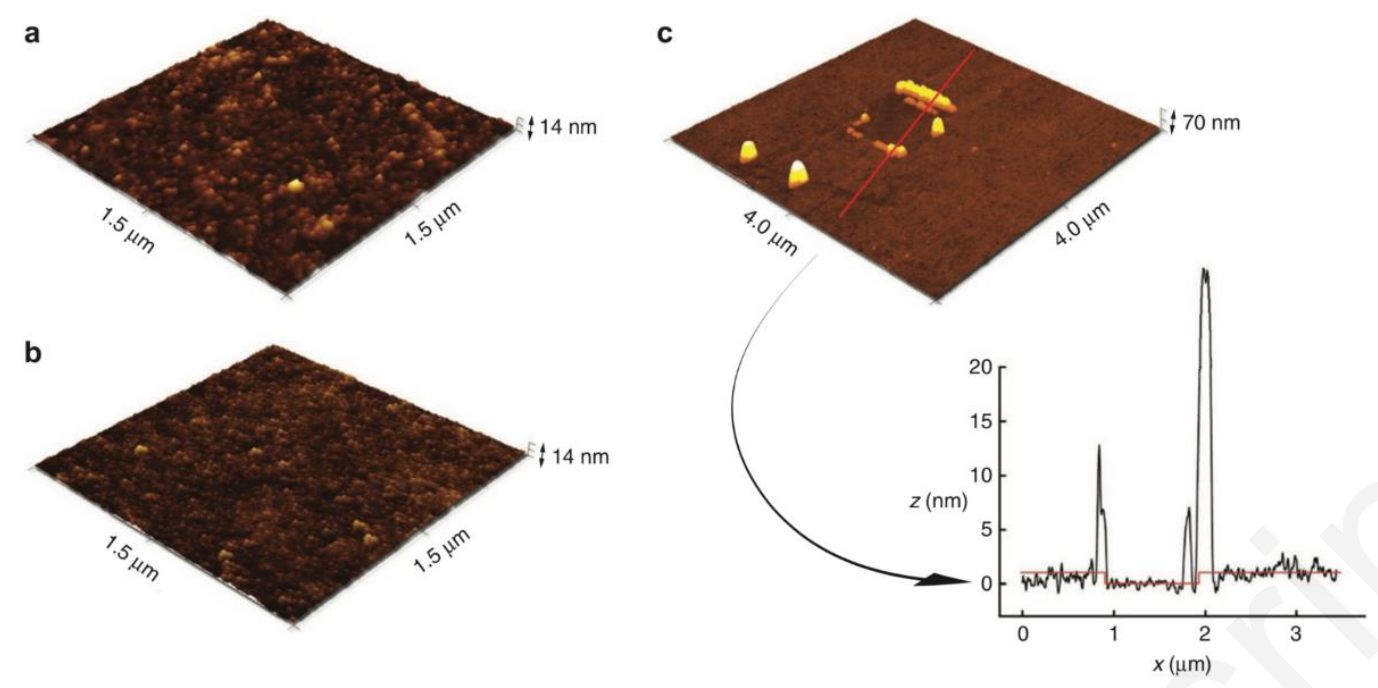

Figure 8. a) AFM image (surface scale $1.5 \times 1.5 \mu \mathrm{m}^{2}$ ) of the bare PPF sample. b) AFM image (surface scale $1.5 \times 1.5$ $\mu \mathrm{m}^{2}$ ) of the PPF sample after in situ generation and electrografting of diazonium cation from 4. c) scratching of the PPF sample as imaged in (b) (surface scale $4 \mathrm{x} 4 \mu \mathrm{m}^{2}$ ). Depth-profile of the scratched area. Reproduced with permission from reference [16]. Copyright 2012 Springer Nature.

Obviously, these techniques do not allow to measure thickness on nanoparticles. In that case, TGA was used on AuNPs-1 to measure grafting densities of 1.5 calixarenes per $\mathrm{nm}^{2}$ that agreed well with the formation of a monolayer. ${ }^{19}$ Similar conclusions were drawn for AuNPs(1 and $\mathbf{8}$ ) by dynamic light scattering (DLS). ${ }^{20}$

Altogether, the use of several analytical techniques confirmed that calix[4]arene derivatives, as those represented in Figure 2, form compact monolayers on conductive, semiconductive and insulating surfaces as well as on nanoparticles.

\section{Formation of mixed monolayers of controlled composition}

The design of thin organic interfaces bearing different functional groups is of great interest for the development of sensors and biosensors. Typically, control over the density of reactive functional groups that can allow the anchoring of recognition systems is usually required to improve the sensor sensitivity ${ }^{63,}{ }^{64}$ For example, diluting the elements of recognition at the interface of the sensor might allow for better accessibility of the analytes in solution. Nonetheless, the formation of mixed layers on surfaces is challenging. For example, if a mixed 
layer of thiols on gold can be prepared by co-adsorption of mixtures of thiols, this approach suffers however from many drawbacks as different thiols derivatives exhibit different adsorption kinetics, hence generating surface coverages with proportions of thiols that are different from solution. ${ }^{65-67}$ More importantly, adsorbed thiols tend to segregate upon selfassembly, leading to inhomogeneous distribution of functions across the surface. ${ }^{68,69}$ The formation of binary mixed layers with a control of the surface composition is even more challenging to achieve with diazonium (electro-)grafting in a one-step procedure because of the high and unselective reactivity of the generated aryl radicals. Indeed, the surface concentration of the component corresponding to the diazonium cations that are the easiest to reduce is generally higher than its mole fraction in the solution. ${ }^{70,} 71$ The use of calix[4]arene tetradiazonium salts constitute a unique approach by taking benefit of the close reduction potentials of these compounds. This is due to the common macrocyclic scaffold that sterically insulates the diazonium groups from the other functional groups. Besides, the covalent grafting between the surface and the calix[4]arene prevents segregation. This was recently observed for the electrografting of in situ generated calix[4]arenes 1 and $4 .{ }^{17}$ Surface functionalization was performed by chronoamperometry at an applied potential of $-0.5 \mathrm{~V}$ vs SCE for 5 minutes. The chemical composition was varied between the two calix[4]arenes following ratios of 100/0, $50 / 50,10 / 90$ and $0 / 100$. Transfer of calix[4]arene ratios in solution to surface ratios was evidenced by contact angle measurements (Figure 9). Indeed, the static contact angle was found to gradually increase from $68 \pm 3^{\circ}$ to $89 \pm 2^{\circ}$ by following Israelachvili's law as the proportion of non-polar calix[4]arene 4 was increased 


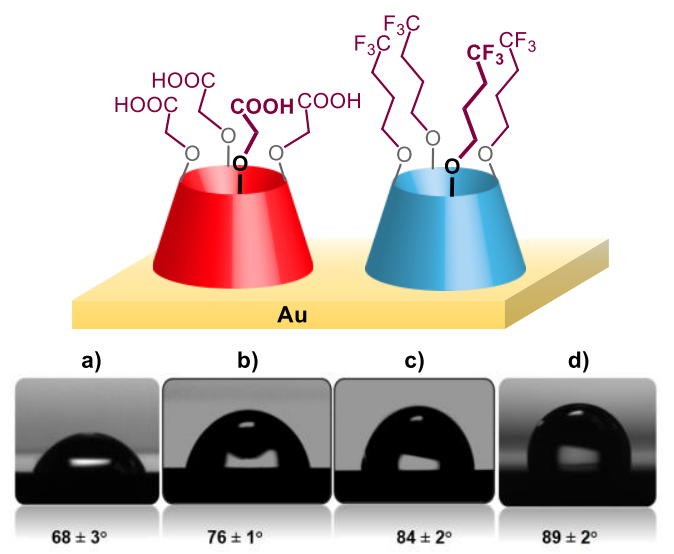

Figure 9. Profile of a $2 \mu \mathrm{L}$ water droplet in contact with a gold substrate modified with calixarenes $\mathbf{1}$ and $\mathbf{4}$ in ratios of a) 100/0, b) 50/50, c) 10/90 and d) 0/100. Adapted with permission from reference [17]. Copyright 2014 American Chemical Society.

A similar approach was used for the formation of AuNPs capped with mixed proportions of calix[4]arenes $\mathbf{1}$ and $\mathbf{8}$ (Figure 10). ${ }^{20}$ Here again, the formation of Au-C covalent bonds presents many advantages compared to similar approaches developed with thiols. Ligand exchange between citrate-capped AuNPs (diameter = $17 \mathrm{~nm}$ ) and calix[4] arenes 1 and 8 (with 1:8 ratios of $0 / 100,5 / 95,10 / 90,25 / 75,50 / 50$, and 100/0) in the presence of $\mathrm{NaBH}_{4}$ led to different batches of AuNPs-calix. These gold nanoparticles were characterized by transmission electron microscopy (TEM) and TGA. In the case of AuNPs-8, TGA showed that an average of 600 calixarenes were present at the AuNPs surface. This corresponds to a grafting density of 0.7 calixarene per $\mathrm{nm}^{2}$. For AuNPs-1, a grafting density of 1.5 calixarene per $\mathrm{nm}^{2}$ was obtained. The difference in the two grafting densities most likely stemmed from differences in steric bulk caused by the four oligoethylene chains. 


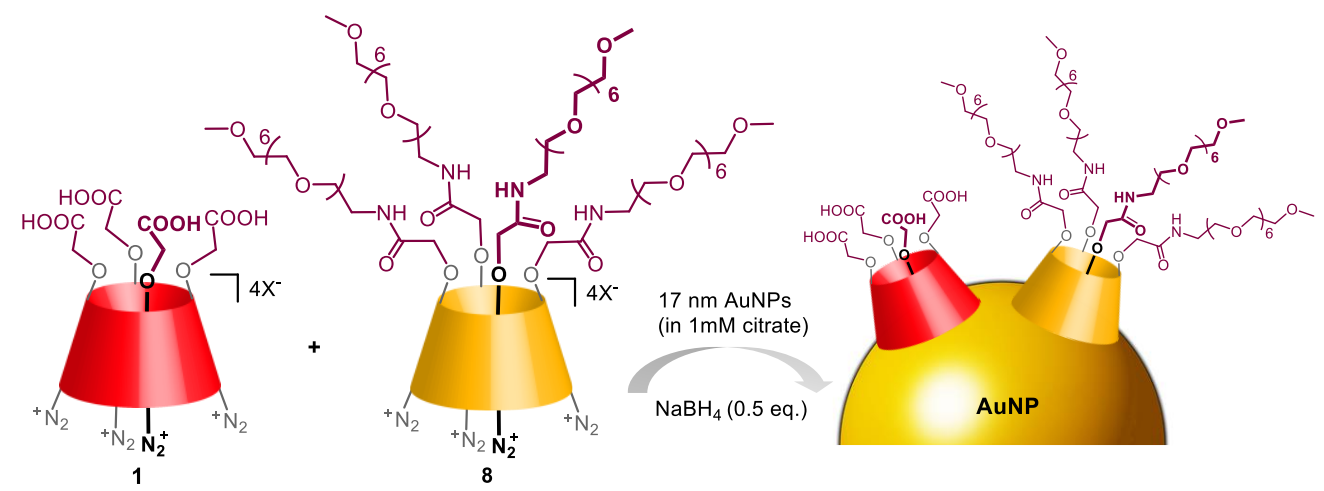

Figure 10. Schematic representation of the grafting of calix[4]arenes $\mathbf{1}$ and $\mathbf{8}$ on citrate-protected AuNPs in aqueous solutions.

Transfer from calix[4]arene solution ratios to surface ratios was confirmed by attenuated total reflectance Fourier transform infrared (ATR-FTIR) spectroscopy. Calix[4]arene 8 exhibited characteristic IR bands at $1105 \mathrm{~cm}^{-1}$ (asymmetric COC stretching) as well as at 1669 $\mathrm{cm}^{-1}$ (amide I) and $1540 \mathrm{~cm}^{-1}$ (amide II). Bands at $1604 \mathrm{~cm}^{-1}$ (asymmetric stretching) and 1420 $\mathrm{cm}^{-1}$ (symmetric stretching) were observed for calix[4]arene $\mathbf{1}$. The intensity of these different characteristic bands was used to evaluate the ratios of calix[4]arenes present at the surface of AuNPs. Interestingly, using a 50/50 mixture of calix[4]arenes $\mathbf{1}$ and $\mathbf{8}$ resulted in equal distribution at the gold surface ( $46 \pm 5 \%$ of 1 ). Small discrepancies were observed when a 5/95 mixture of calix[4]arenes $\mathbf{1}$ and $\mathbf{8}$ was used. In that case, the concentration of calix[4]arene $\mathbf{1}$ at the surface was roughly twice that found in solution. This was rationalized through the grafting density of $\mathbf{1}$ that was roughly double that of $\mathbf{8}\left(1.5\right.$ vs 0.7 calixarene per $\left.\mathrm{nm}^{2}\right)$. Hence, at high concentration of $\mathbf{8}$, the remaining unmodified gold surface was more efficiently modified by $\mathbf{1}$.

\section{Post-functionalization of calixarene-based monolayers}

Additional properties could be introduced through post-functionalization of the calix-based layer, provided that the small rim of the calixarene derivatives was decorated with reactive functional groups. ${ }^{13,14,16-20}$ Typical groups for post-functionalization include, but are not limited to, carboxylic acids, azides and alkynes. Carboxylic acids can react through peptide- 
type coupling to generate an amide bond whereas alkynes or azides can be engaged in click or electroclick chemistry to form the corresponding triazole moiety. The post-functionalization with electro-active probes can be used to determine surface concentrations of grafted molecules. For example, in the case of mixed layers of calix[4]arenes $\mathbf{1}$ and $\mathbf{4}$, carboxylic acid moieties were post-functionalized with ferrocenepentylamine $\left(\mathrm{Fc}-\mathrm{C}_{5} \mathrm{H}_{10}-\mathrm{NH}_{2}\right)$, using oxalyl chloride and pyridine in dichloromethane (Figure 11). ${ }^{17}$ This reaction was carried out on gold surfaces with 1:4 ratios of 100/0, 50/50 and 10/90. Cyclic voltammetry of the ferrocene-modified electrodes in dichloromethane containing $0.2 \mathrm{M}^{t} \mathrm{Bu}_{4} \mathrm{NPF}_{6}$ yielded an electrochemical response at $0.35 \mathrm{~V}$ vs SCE, consistent with the surface-confined ferrocene-ferrocenium couple. In the case of a surface modified with calix[4]arene 1 , a surface concentration of $\Gamma_{1}=2.1 \pm 0.7 \times 10^{-10}$ mol cm$~^{-2}$ was determined for the ferrocene by voltammetric peak integration, indicating that more than two carboxyl moieties reacted with ferrocenepentylamine. For the surfaces modified with 1:4 in ratios of 50/50 and 10/90, surface concentrations of $\Gamma_{50 / 50}=1.01 \pm 0.4 \times 10^{-10} \mathrm{~mol}$ $\mathrm{cm}^{-2}$ and $\Gamma_{10 / 90}=5.1 \pm 0.4 \times 10^{-11} \mathrm{~mol} \mathrm{~cm}^{-2}$ were determined, respectively. $\Gamma_{50 / 50}$ values were approximately half of that measured for $\Gamma_{1}$, in agreement with a 1:1 distribution on the surface. $\Gamma_{10 / 90}$ was found to be almost twice as high as the expected value, which suggested that chemical coupling of ferrocenepentylamine is easier when the immobilized calix[4]arene $\mathbf{1}$ is more diluted at the surface. 


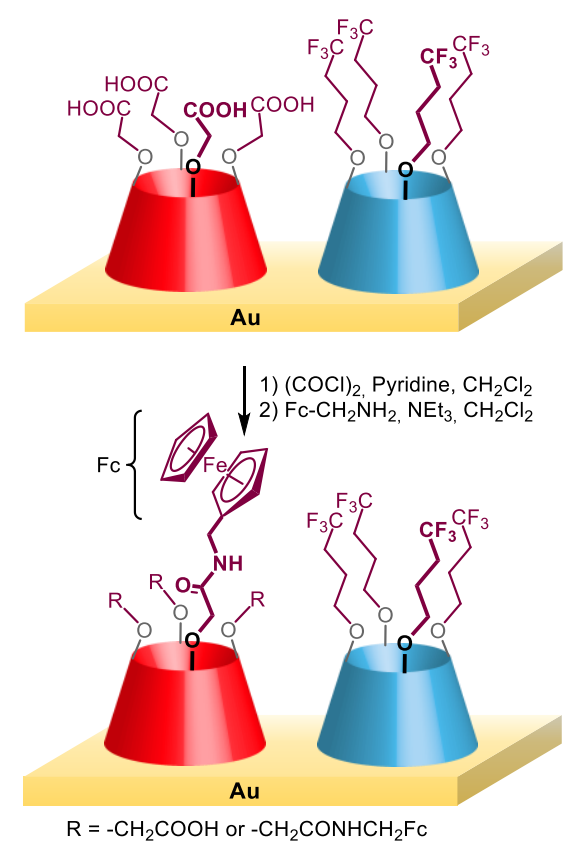

Figure 11. Chemical post-functionalization of mixed calixarene-based monolayers with ferrocenepentylamine.

In the case of AuNPs-1 for example, a peptide-like coupling using EDC and NHS was carried out with dodecylamine at room temperature. ${ }^{19}$ The as-modified AuNPs became insoluble in water, but soluble in diethylether. Similar post-functionalization strategy was performed on polypropylene surfaces functionalized with calix[4]arene $1 .{ }^{18}$ The activated ester generated in aqueous buffer was dried and further reacted with 4,4,4-trifluorobutylamine or 4,4,4-trifluoro-1-butanol in dichloromethane at room temperature. Finally, calix[4]arenemodified surfaces bearing alkyne functions were post-functionalized with azidomethylferrocene through click chemistry. ${ }^{13,14}$ The modified surfaces gave a reversible electrochemical response corresponding to the ferrocene/ferrocenium couple. Surface concentrations of ferrocene which support the formation of a compact monolayer of calixarenes were determined using the integrated voltammetric peak currents. 


\section{Robustness of the calixarene-based coatings}

Until now, calix[4]arenes have been covalently grafted on surfaces that include: gold, pyrolyzed photoresist films (PPF), glassy carbon, glass, germanium, polypropylene, polyethylene terephthalate, polystyrene and gold nanoparticles. ${ }^{12-20}$ The calix[4]arene-based monolayers are very stable, as post-grafting workup typically includes thorough washing cycles using sonication ranging between 10 and $30 \mathrm{~min}$ in a variety of solvents that include: water, ethanol, dichloromethane, acetonitrile, tetrahydrofuran, 0.1 M hydrochloric acid and toluene. Additionally, germanium surfaces modified with calix[4]arenes 6 and 7 were exposed to a continuous flow $(10 \mu \mathrm{L} / \mathrm{min})$ of $\mathrm{PBS}-\mathrm{D}_{2} \mathrm{O}$ buffer for $16 \mathrm{~h}$ while recording infrared spectra. Difference infrared spectra recorded over time revealed that the grafted layer remained covalently attached under these conditions. The robustness clearly originates from the multiple covalent bonds that are formed between the multivalent calixarene platform and the surface upon grafting.

This robustness is even more impressive in the case of AuNPs. ${ }^{19,}{ }^{20}$ In strong contrast with AuNPs stabilized with citrate or thiols that are usually sensitive to $\mathrm{pH}$ changes, AuNPs-(1 or 8) could be reversibly suspended and precipitated when the $\mathrm{pH}$ was changed between 0.75 and 13 (Figure 12, top and middle). Even more remarkably, AuNPs-(1 or 8) remained stable in presence of large concentrations of fluoride ions (between 0.15 and $0.75 \mathrm{M}$ ) whereas hepta(ethylene glycol)thiol modified AuNPs aggregated when $0.3 \mathrm{M} \mathrm{KF}$ was added. ${ }^{19,20}$ Additionally, AuNPs-calix show excellent stability towards ionic strength changes. They can also be dried (forming a gold-colored film) and then resuspended into a $0.1 \mathrm{M}$ aqueous $\mathrm{NaOH}$ solution (Figure 12, bottom). 

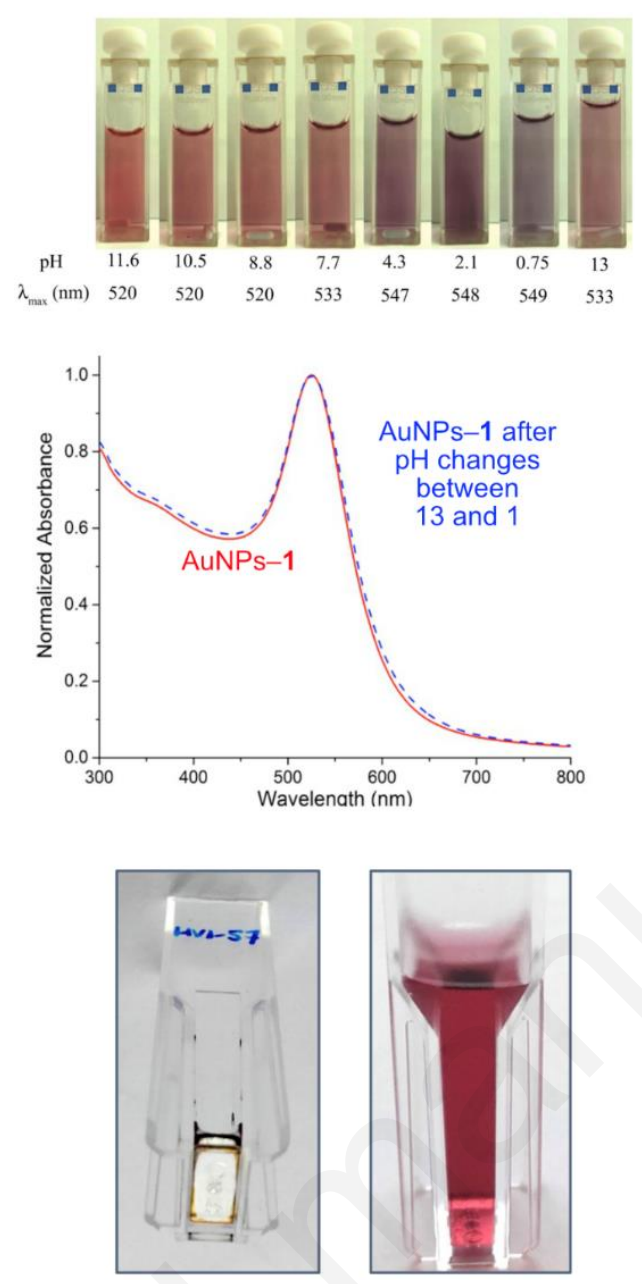

Figure 12. (Top) Photographs of aqueous solutions of AuNPs coated with calix[4]arene 1 at different pHs. Normalized UV-Visible absorption spectra (middle) of AuNPs coated with calix[4]arene 1 after several pH changes between 13 and 1. Dried AuNPs coated with calix[4]arene 1 and resuspended in $0.1 \mathrm{M}$ aqueous $\mathrm{NaOH}$ (bottom). Reproduced with permission from reference [19]. Copyright 2016 Royal Society of Chemistry.

\section{Applications of calixarene-based coatings}

Surface modification with calix[4]arene derivatives has found applications in the development of hydrophobic surfaces, ${ }^{61}$ sensors with antifouling properties ${ }^{12}$ or sensors for the detection of primary alkylamines in water. ${ }^{14}$

Hydrophobic surfaces. The development of surfaces with controlled wettability ${ }^{72-74}$ is of great importance for applications such as anti-biofouling, ${ }^{12,75}$ anti-frosting and anti-fogging, ${ }^{76,}$ 77 self-cleaning, ${ }^{78}$ anti-corrosion, ${ }^{79,}{ }^{80}$ or water-proof functions. ${ }^{81}$ Wettability is usually characterized by static contact angle measurements. Common denominations include superhydrophilicity, with contact angles smaller than $10^{\circ}$, superhydrophobicity, with contact 
angles greater than $150^{\circ}$ and negligible adhesion forces. Superhydrophobicity can be typically achieved by covering a nano-structured surface with polyfluorinated molecules. On smooth surfaces, a maximized static contact angle of roughly $120^{\circ}$ has been determined. In this regard, calix[4]arene derivative bearing polyfluorinated alkyl chains $\mathbf{5}$ was recently developed and covalently grafted on glass, gold and polypropylene. ${ }^{61}$ The grafting was achieved either electrochemically, when possible, or using a $\mathrm{MeCN} / 0.1 \mathrm{M} \mathrm{NaOH}$ aqueous solution. The formation of a monolayer was confirmed by AFM and ellipsometry. This monolayer led to drastic changes of the static contact angle, most notably for gold and glass surfaces (Figure 13). On gold, the unmodified surface was characterized by contact angles of $64.7 \pm 2.1^{\circ}$ whereas the modified surface reached values of $113.7 \pm 2.2^{\circ}$. In the case of glass, the static contact angle changed from $24.6 \pm 2.0^{\circ}$ to $110.0 \pm 1.8^{\circ}$ for the unmodified and modified surfaces respectively. In the case of polypropylene, only a marginal increase was observed as the unmodified surface is already hydrophobic, with static contact angle that evolved from $102.9 \pm 3.9^{\circ}$ to $112.6 \pm 4.0^{\circ}$. Preliminary ageing studies were conducted. The coated surfaces were left under laboratory atmosphere for eighteen months. Remarkably, static contact angles of these aged surfaces were within $5 \%$ of the values obtained for freshly modified surfaces. The use of polyfluorinatedcalixarene-based surfaces open thus interesting perspectives in the design of robust hydrophobic surfaces on a wide range of materials.
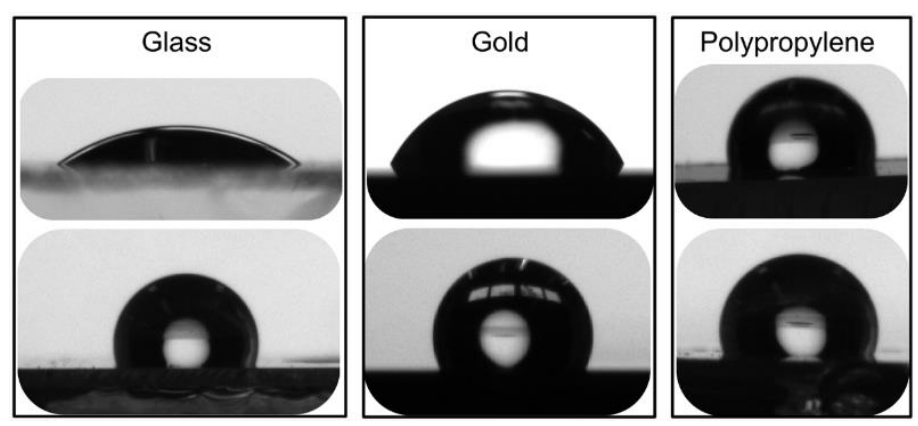

Figure 13. Images of $2 \mu \mathrm{L}$ water droplets in contact with (top) bare glass, gold and polypropylene surfaces and with (bottom) the same surfaces modified with calix[4]arene 5. ${ }^{[61]}$ 
Antifouling coatings. Germanium represents an attractive material for the development of biosensors using ATR-FTIR spectroscopy, as it exhibits a large refractive index and allows measurements in a wide spectral window that encompasses 4000 to $700 \mathrm{~cm}^{-1}$. On the other hand, oligo-(ethylene glycol)s (oEGs) are nontoxic and nonimmunogenic compounds that are known to prevent the non-specific adsorption of proteins and biomacromolecules. In this context, calix[4]arenes bearing oEG chains, 6 and 7, were recently used for the design of germanium-based surfaces displaying remarkable antifouling properties (Figure 14). The covalent grafting of a monolayer was demonstrated by AFM. Infrared absorption spectra of the modified germanium surfaces confirmed the efficient grafting of calix[4]arenes 6 and 7 with typical asymmetric COC stretching from the oEG chains around $1100 \mathrm{~cm}^{-1}$ as well as other bands ranging from 1050 to $1020 \mathrm{~cm}^{-1}$ (symmetric COCAr stretching) and at $1460 \mathrm{~cm}^{-1}$ (aromatic ring stretching).

A solution of bovine serum albumin (BSA, $100 \mu \mathrm{g} / \mathrm{mL}$ ), the most abundant protein in blood, in phosphate buffer media in $\mathrm{D}_{2} \mathrm{O}\left(\mathrm{PBS}-\mathrm{D}_{2} \mathrm{O}\right)$ at $22{ }^{\circ} \mathrm{C}$ was then used to study the nonspecific adsorption properties of the calixarene-based germanium surfaces. Infrared spectra were recorded at specific time intervals where the non-specific adsorption of bovine serum albumin was evidenced by the increased contribution over time of absorption bands at $1640 \mathrm{~cm}^{-1}$ (amide-I', $\mathrm{C}=\mathrm{O}(\mathrm{ND})$ stretching vibrations) and at $1450 \mathrm{~cm}^{-1}$ (amide-II', in plane ND bending vibrations). Remarkably, the presence of covalently grafted calix[4]arene-oEGs decreased the non-specific adsorption of BSA by more than $85 \%$ compared to unmodified germanium surfaces. Hence, the $2.4 \mathrm{~nm}$ thick monolayer of calix[4]arene derivatives functionalized with oligo-(ethylene glycol) chains yielded remarkable antifouling properties that predicts exciting opportunities for the development of biosensors. 


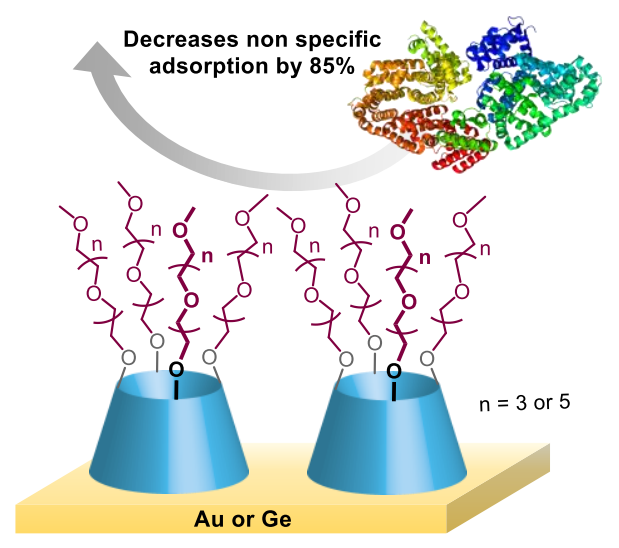

Figure 14. Antifouling properties of calixarene-oEGs-based coatings. Reproduced with permission from reference [12]. Copyright 2018 American Chemical Society.

Electrochemical sensing in water. Host-guest chemistry at the interface represents an attractive research area for the development of sensors and heterogeneous catalysts. Funnel complexes ${ }^{57}$ i.e. calix[6]arene-based metal complexes mimicking the transport path to the active site of metallo-enzymes through the introduction of a hydrophobic corridor, have been used in this context. ${ }^{14}$ These funnel complexes are efficient receptors for neutral molecules such as amines through the formation of a coordination bond between the metallic center and the guest. Here, gold electrodes coated by a monolayer of calix[4]arenes bearing alkyne groups ${ }^{14}$ were modified through an electro-click reaction with a calix[6]azacryptand bearing an azide group (Figure 15). These modified electrodes were then investigated for the selective electrochemical sensing of primary amines at micromolar concentrations in aqueous solutions. The study was also performed in organic solvents whereas stability issues prevented similar measurements using related thiol-modified gold surfaces. In the presence of primary amines, the electrochemical response associated with the $\mathrm{Cu}(\mathrm{II}) / \mathrm{Cu}(\mathrm{I})$ redox potential shifted by 100 $\mathrm{mV}$, indicative of amine binding to the $\mathrm{Cu}$ center. Primary alkylamines were selectively recognized by calix[6]azacryptand moiety whereas bulky primary amines or linear polyamines, such as spermine and spermidine were not. 


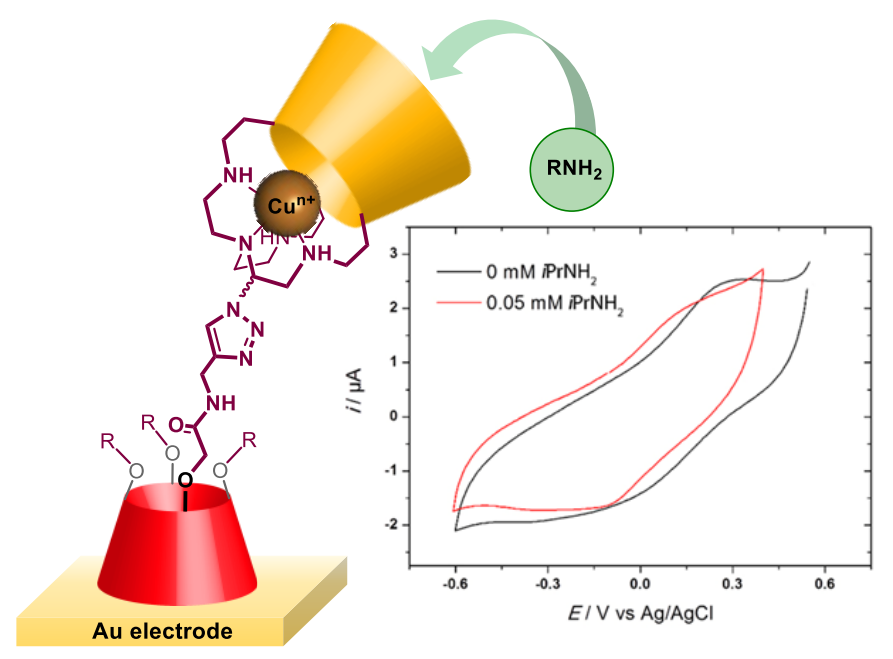

Figure 15. Selective electrochemical sensing of primary amines. Reproduced with permission from ref [14]. Copyright 2016 American Chemical Society.

\section{Conclusions and future directions}

Covalent surface modification of any kind of materials with monolayers of controlled composition that can be further post-functionalized represents an active area of research. The objectives are the formation of highly robust interfaces, key point for any applications, and the facile introduction of tailored properties. In this context, the molecular strategy overviewed in this paper is particularly appealing. Over ten derivatives of calix [4 or 6]arene have been successfully covalently grafted on a wide range of materials including: gold, pyrolyzed photoresist films (PPF), glassy carbon, glass, germanium, polypropylene, polyethylene terephthalate, polystyrene and gold nanoparticles. Further post-functionalization of carboxylic acid moieties, through peptide-like coupling or using oxalyl chloride, or azide and alkyne groups, through click chemistry, has been achieved. These tailored surfaces served as proof-ofconcept for early applications such as the recognition of guests in water, antifouling of biomolecules and the formation of hydrophobic surfaces.

The strategy based on calix[4]arene tetradiazonium salts is especially versatile: it takes benefit from a "pre-organized" approach thanks to the unique structure of these macrocycles, the multiple anchoring points at the large rim and the possibility to introduce functional objects 
with a fine spatial control imposed by the small rim geometry. Hence, the strategy is expected to further bring advances in the field of biosensing and molecular recognition. Thus, in the field of nanoparticles a drastic gain in robustness has been evidenced for the calixarenefunctionalized gold colloids compared to corresponding state-of-the-art thiol derivatives. The possibility to electrochemically or chemically graft mixed monolayers with controlled composition is a very attractive and unique method to design molecular approaches for diagnostic and dual recognition. Hence, the covalent grafting of calixarene derivatives is an area ripe for research with tremendous promising opportunities for future developments. Current efforts undertaken in our laboratories aim at moving this technology one step further by post-functionalizing covalently bound calix[4]arene derivatives with biomolecules to develop efficient sensors for diagnosis and biomedical applications. Additionally, we are currently seeking to expand this technology on various metal nanoparticles for applications in medicine and catalysis.

10. Conflict of Interest: L. T.-G. was a postdoctoral researcher for X4C between October 2014 and September 2015. I. J., O.R., A.M. and C. L. are shareholders of X4C. I. J. is a consultant for X4C. All other authors declare that they have no conflict of interest.

\section{Acknowledgements}

L. T.-G. is a Postdoctoral researcher of the Fonds de la Recherche Scientifique - FNRS.

\section{Biography}




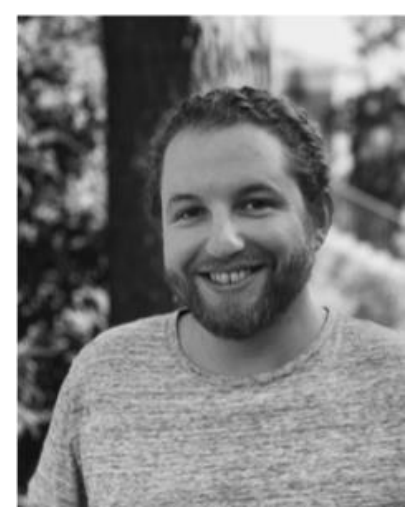

Ludovic Troian-Gautier received his B.Sc. (2008), M.Sc (2010), and Ph.D. in chemistry (2014) under the supervision of Prof. C. Moucheron from the Université libre de Bruxelles (ULB). He undertook postdoctoral research (2014-2015) with Prof. I. Jabin, where he worked on surface modification using calix[4]arene derivatives. Between 2015 and 2019, he performed research within the Alliance for Molecular PhotoElectrode Design for Solar Fuels (AMPED EFRC) directed by Prof. G. J. Meyer at the University of North Carolina at Chapel Hill. In May 2019, he started a Chargé de Recherche position (FNRS) at ULB where he works on energy related challenges.

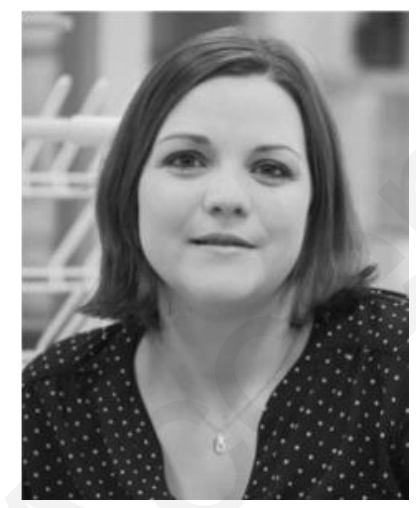

Alice Mattiuzzi received her Ph.D. in Chemistry (2012) from the Universite libre de Bruxelles (ULB) under the supervision of Prof. Ivan Jabin where she developed skills in organic synthesis and surface modification. Between 2012 and 2016 she was awarded a "first spin-off" grant that led to the establishment of $\mathrm{X} 4 \mathrm{C}$, a company that offers innovative surface coating solutions for high-end applications. Since 2016, she is CEO of X4C. 


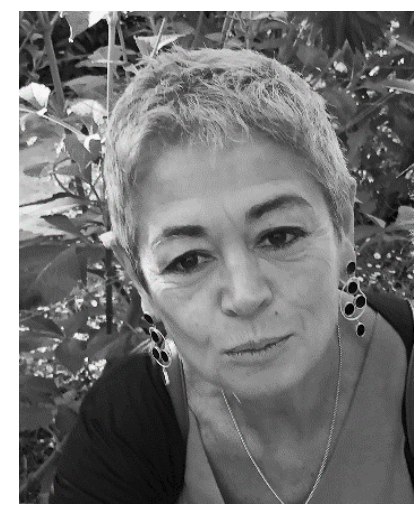

Olivia Reinaud obtained her $\mathrm{PhD}$ in organic chemistry in 1987 from the « Ecole supérieure de physique et de chimie industrielles - Université Pierre et Marie Curie » (ESPCI-UPMC). After a one-year postdoctoral experience in biochemistry at Paris Descartes University, she was appointed CNRS researcher and developed novel biomimetic copper catalyzed processes at ESPCI. As a CNRS researcher, she undertook a two-year sabbatical at Delaware University, working with Prof. K. Theopold in inorganic chemistry. In 2001, she was appointed professor at Paris Descartes University where she develops "Supramolecular Bio-Inorganic Chemistry", dealing with biomimetic metal complexes based on calixarene derivatives.

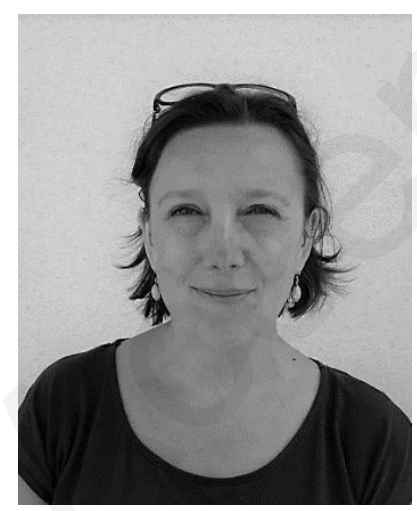

Corinne Lagrost gained her Ph. D degree in 2000 from Denis Diderot University (Paris, France) in the areas of conducting polymers and supramolecular chemistry. After one-year postdoctoral research at the University of Amsterdam (The Netherlands), she joined CNRS and took up a permanent researcher position at the Institute of Chemical Sciences in Rennes 
(France) where she is currently Directrice de recherche. She has broad ranging interests in electrochemistry, mainly focusing on electrochemical reactivity in non-conventional media (ionic liquids, DES) and surface functionalization (surface modification and properties characterization).

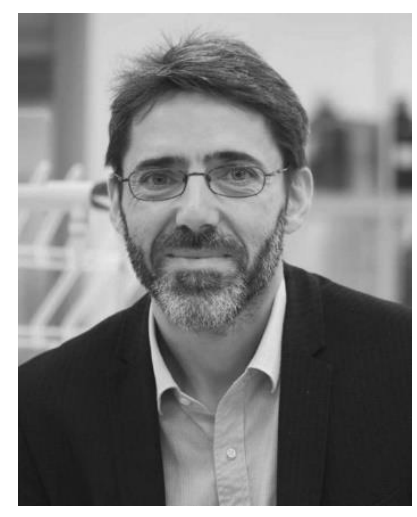

Ivan Jabin obtained his $\mathrm{PhD}$ in Organic Chemistry from the Pierre et Marie Curie University (France) in 1996. After two years as a post-doctoral fellow, first at Lehigh University (USA) and then at the Conservatoire National de Paris des Arts et Métiers (France), he was appointed assistant Professor of Chemistry at the University of Le Havre (France). In 2006, he joined the Université libre de Bruxelles (ULB, Belgium) as a full Professor. His current research interests include the synthesis and study of new classes of molecular receptors as well as the development of surface with tailored properties.

\section{References}

1. M. Delamar, R. Hitmi, J. Pinson and J. M. Saveant, J. Am. Chem. Soc., 1992, 114, 5883-5884.

2. D.-e. Jiang, B. G. Sumpter and S. Dai, J. Am. Chem. Soc., 2006, 128, 6030-6031.

3. D.-e. Jiang, B. G. Sumpter and S. Dai, J. Phys. Chem. B, 2006, 110, 23628-23632.

4. S. Mahouche-Chergui, S. Gam-Derouich, C. Mangeney and M. M. Chehimi, Chem. Soc. Rev., 2011, 40, 4143-4166.

5. D. Bélanger and J. Pinson, Chem. Soc. Rev., 2011, 40, 3995-4048.

6. A. A. Mohamed, Z. Salmi, S. A. Dahoumane, A. Mekki, B. Carbonnier and M. M. Chehimi, Adv. Colloid Interfac., 2015, 225, 16-36.

7. S. Hebié, A. K. D. Dimé, C. H. Devillers and D. Lucas, Chem. Eur. J., 2015, 21, 8281-8289.

8. A. J. Gross, C. Bucher, L. Coche-Guerente, P. Labbé, A. J. Downard and J.-C. Moutet, Electrochem. Commun., 2011, 13, 1236-1239.

9. M. Picot, I. Nicolas, C. Poriel, J. Rault-Berthelot and F. Barrière, Electrochem. Commun., 2012, 20, 167170. 
10. Y.-S. Kim, S. Fournier, S. Lau-Truong, P. Decorse, C. H. Devillers, D. Lucas, K. D. Harris, B. Limoges and V. Balland, ChemElectroChem, 2018, 5, 1625-1630.

11. C. Cannizzo, M. Wagner, J.-P. Jasmin, C. Vautrin-U1, D. Doizi, C. Lamouroux and A. Chaussé, Tetrahedron Letters, 2014, 55, 4315-4318.

12. P. Blond, A. Mattiuzzi, H. Valkenier, L. Troian-Gautier, J.-F. Bergamini, T. Doneux, E. Goormaghtigh, V. Raussens and I. Jabin, Langmuir, 2018, 34, 6021-6027.

13. J. P. Buttress, D. P. Day, J. M. Courtney, E. J. Lawrence, D. L. Hughes, R. J. Blagg, A. Crossley, S. E. Matthews, C. Redshaw, P. C. Bulman Page and G. G. Wildgoose, Langmuir, 2016, 32, 7806-7813.

14. G. De Leener, F. Evoung-Evoung, A. Lascaux, J. Mertens, A. G. Porras-Gutierrez, N. Le Poul, C. Lagrost, D. Over, Y. R. Leroux, F. Reniers, P. Hapiot, Y. Le Mest, I. Jabin and O. Reinaud, J. Am. Chem. Soc., 2016, 138, 12841-12853.

15. V. Malytskyi, L. Troian-Gautier, A. Mattiuzzi, S. Lambotte, B. Cornelio, C. Lagrost and I. Jabin, Eur. J. Org. Chem., 2018, 2018, 6590-6595.

16. A. Mattiuzzi, I. Jabin, C. Mangeney, C. Roux, O. Reinaud, L. Santos, J.-F. Bergamini, P. Hapiot and C. Lagrost, Nat. Commun., 2012, 3, 1130.

17. L. Santos, A. Mattiuzzi, I. Jabin, N. Vandencasteele, F. Reniers, O. Reinaud, P. Hapiot, S. Lhenry, Y. Leroux and C. Lagrost, J. Phys. Chem. C, 2014, 118, 15919-15928.

18. L. Troian-Gautier, D. E. Martínez-Tong, J. Hubert, F. Reniers, M. Sferrazza, A. Mattiuzzi, C. Lagrost and I. Jabin, J. Phys. Chem. C, 2016, 120, 22936-22945.

19. L. Troian-Gautier, H. Valkenier, A. Mattiuzzi, I. Jabin, N. V. den Brande, B. V. Mele, J. Hubert, F. Reniers, G. Bruylants, C. Lagrost and Y. Leroux, Chem. Commun., 2016, 52, 10493-10496.

20. H. Valkenier, V. Malytskyi, P. Blond, M. Retout, A. Mattiuzzi, J. Goole, V. Raussens, I. Jabin and G. Bruylants, Langmuir, 2017, 33, 8253-8259.

21. J. Agullo, S. Canesi, F. Schaper, M. Morin and D. Bélanger, Langmuir, 2012, 28, 4889-4895.

22. H. Smida, E. Lebègue, J.-F. Bergamini, F. Barrière and C. Lagrost, Bioelectrochemistry, 2018, 120, 157 165.

23. C. Rinfray, G. Izzet, J. Pinson, S. Gam Derouich, J.-J. Ganem, C. Combellas, F. Kanoufi and A. Proust, Chem. Eur. J., 2013, 19, 13838-13846.

24. R. Bangle, R. N. Sampaio, L. Troian-Gautier and G. J. Meyer, ACS Appl. Mater. Interfaces, 2018, 10, 3121-3132.

25. Q. Van Nguyen, F. Lafolet, P. Martin and J. C. Lacroix, J. Phys. Chem. C, 2018, 122, $29069-29074$.

26. V. Q. Nguyen, X. Sun, F. Lafolet, J.-F. Audibert, F. Miomandre, G. Lemercier, F. Loiseau and J.-C. Lacroix, J. Am. Chem. Soc., 2016, 138, 9381-9384.

27. C. Wang, M. Amiri, R. T. Endean, O. Martinez Perez, S. Varley, B. Rennie, L. Rasu and S. H. Bergens, ACS Appl. Mater. Interfaces, 2018, 10, 24533-24542.

28. B. P. Corgier, S. Bellon, M. Anger-Leroy, L. J. Blum and C. A. Marquette, Langmuir, 2009, 25, 96199623.

29. B. P. Corgier, C. A. Marquette and L. J. Blum, J. Am. Chem. Soc., 2005, 127, 18328-18332.

30. S. Abdellaoui, B. C. Corgier, C. A. Mandon, B. Doumèche, C. A. Marquette and L. J. Blum, Electroanal., 2013, 25, 671-684.

31. J. A. Belmont, C. Bureau, M. M. Chehimi, S. Gam Derouich and J. Pinson, in Aryl Diazonium Salts, ed. M. M. Chehimi, 2012, DOI: 10.1002/9783527650446.ch14, pp. 309-321.

32. A. Berisha, M. M. Chehimi, J. Pinson and F. Podvorica, in Electroanalytical chemistry, a series of advances eds. A. J. Bard and C. G. Zoski, CRC Press, Taylor \& Francis group, Boca Raton, 2016, vol. 26.

33. P. Hapiot, C. Lagrost and Y. R. Leroux, Current Opinion in Electrochemistry, 2018, 7, $103-108$.

34. C. Jiang, S. Moraes Silva, S. Fan, Y. Wu, M. T. Alam, G. Liu and J. Justin Gooding, Journal of Electroanalytical Chemistry, 2017, 785, 265-278.

35. T. Breton and A. J. Downard, Australian Journal of Chemistry, 2017, 70, 960-972.

36. C. Combellas, F. Kanoufi, J. Pinson and F. I. Podvorica, J. Am. Chem. Soc., 2008, 130, 8576-8577.

37. C. Combellas, D.-e. Jiang, F. Kanoufi, J. Pinson and F. I. Podvorica, Langmuir, 2009, 25, 286-293.

38. L. T. Nielsen, K. H. Vase, M. Dong, F. Besenbacher, S. U. Pedersen and K. Daasbjerg, J. Am. Chem. Soc., 2007, 129, 1888-1889.

39. K. Malmos, M. Dong, S. Pillai, P. Kingshott, F. Besenbacher, S. U. Pedersen and K. Daasbjerg, J. Am. Chem. Soc., 2009, 131, 4928-4936.

40. Y. R. Leroux, H. Fei, J.-M. Noël, C. Roux and P. Hapiot, J. Am. Chem. Soc., 2010, 132, 14039-14041.

41. L. Lee, H. Ma, P. A. Brooksby, S. A. Brown, Y. R. Leroux, P. Hapiot and A. J. Downard, Langmuir, 2014, 30, 7104-7111.

42. Y. R. Leroux and P. Hapiot, Chem. Mater., 2013, 25, 489-495.

43. L. Lee, N. R. Gunby, D. L. Crittenden and A. J. Downard, Langmuir, 2016, 32, 2626-2637. 
44. J. Ghilane, P. Martin, O. Fontaine, J.-C. Lacroix and H. Randriamahazaka, Electrochem. Commun., 2008, 10, 1060-1063.

45. O. Fontaine, J. Ghilane, P. Martin, J.-C. Lacroix and H. Randriamahazaka, Langmuir, 2010, 26, 1854218549.

46. G. Shul, C. A. C. Ruiz, D. Rochefort, P. A. Brooksby and D. Bélanger, Electrochim. Acta, 2013, 106, 378-385.

47. J. Carvalho Padilha, J.-M. Noël, J.-F. Bergamini, J. Rault-Berthelot and C. Lagrost, ChemElectroChem, 2016, 3, 572-580.

48. T. Menanteau, E. Levillain and T. Breton, Chem. Mater., 2013, 25, 2905-2909.

49. T. Menanteau, E. Levillain and T. Breton, Langmuir, 2014, 30, 7913-7918.

50. T. Menanteau, E. Levillain, A. J. Downard and T. Breton, Phys. Chem. Chem. Phys., 2015, 17, $13137-$ 13142.

51. I. López, M. Cesbron, E. Levillain and T. Breton, ChemElectroChem, 2018, 5, 1197-1202.

52. L. Santos, J. Ghilane, P. Martin, P.-C. Lacaze, H. Randriamahazaka and J.-C. Lacroix, J. Am. Chem. Soc., 2010, 132, 1690-1698.

53. L. Santos, J. Ghilane and J. C. Lacroix, J. Am. Chem. Soc., 2012, 134, 5476-5479.

54. C. D. Gutsche, Calixarenes Revisited, Monographs in Supramolecular Chemistry, The Royal Society of Chemistry, Cambridge, 1998.

55. Z.-Q. Li, J.-H. Tang and Y.-W. Zhong, Chem. Asian J., 2019, 14, 3119-3126.

56. A. Ikeda and S. Shinkai, Chem. Rev., 1997, 97, 1713-1734.

57. N. Le Poul, Y. Le Mest, I. Jabin and O. Reinaud, Acc. Chem. Res, 2015, 48, 2097-2106.

58. Unpublished results. TGA analyses on compound 4 were performed on a Perkin Elmer Pyris 6 TGA device. For this purpose, 4 to $6 \mathrm{mg}$ of the material weighed in a ceramic crucible Perkin Elmer TGA underwent a linear ramp of increasing temperature up to $550^{\circ} \mathrm{C}$ at a rate of $10^{\circ} \mathrm{C} \cdot \mathrm{min}^{-1}$ under nitrogen inert atmosphere. The obtained results were then processed with the Pyris Manager software.

59. S. H. DuVall and R. L. McCreery, Anal. Chem., 1999, 71, 4594-4602.

60. J. Pinson and F. Podvorica, Chem. Soc. Rev., 2005, 34, 429-439.

61. A. Mattiuzzi, L. Troian-Gautier, J. Mertens, F. Reniers, J.-F. Bergamini, Q. Lenne, C. Lagrost and I. Jabin, $R S C A d v$., 2020, Submitted.

62. F. Anariba, S. H. DuVall and R. L. McCreery, Anal. Chem., 2003, 75, 3837-3844.

63. Liu and J. J. Gooding, Langmuir, 2006, 22, 7421-7430.

64. S. M. Khor, G. Liu, C. Fairman, S. G. Iyengar and J. J. Gooding, Biosens. Bioelectron., 2011, 26, 20382044.

65. P. E. Laibinis, M. A. Fox, J. P. Folkers and G. M. Whitesides, Langmuir, 1991, 7, 3167-3173.

66. P. E. Laibinis, R. G. Nuzzo and G. M. Whitesides, J. Phys. Chem., 1992, 96, 5097-5105.

67. J. C. Love, L. A. Estroff, J. K. Kriebel, R. G. Nuzzo and G. M. Whitesides, Chem. Rev., 2005, 105, 11031170.

68. S. J. Stranick, A. N. Parikh, Y. T. Tao, D. L. Allara and P. S. Weiss, J. Phys. Chem., 1994, 98, 76367646.

69. S.-i. Imabayashi, D. Hobara, T. Kakiuchi and W. Knoll, Langmuir, 1997, 13, 4502-4504.

70. G. Liu, M. Chockalingham, S. M. Khor, A. L. Gui and J. J. Gooding, Electroanal., 2010, 22, 918-926.

71. C. Louault, M. D'Amours and D. Bélanger, ChemPhysChem, 2008, 9, 1164-1170.

72. X.-M. Li, D. Reinhoudt and M. Crego-Calama, Chem. Soc. Rev., 2007, 36, 1350-1368.

73. S. Wang, K. Liu, X. Yao and L. Jiang, Chem. Rev., 2015, 115, 8230-8293.

74. J. Yong, F. Chen, Q. Yang, J. Huo and X. Hou, Chem. Soc. Rev., 2017, 46, 4168-4217.

75. I. Banerjee, R. C. Pangule and R. S. Kane, Adv. Mater., 2011, 23, 690-718.

76. A. Kim, C. Lee, H. Kim and J. Kim, ACS Appl. Mater. Interfaces, 2015, 7, 7206-7213.

77. J. A. Howarter and J. P. Youngblood, Adv. Mater., 2007, 19, 3838-3843.

78. P. Ragesh, V. Anand Ganesh, S. V. Nair and A. S. Nair, J. Mater. Chem. A, 2014, 2, 14773-14797.

79. F. Xiao, S. Yuan, B. Liang, G. Li, S. O. Pehkonen and T. Zhang, J. Mater. Chem. A, 2015, 3, 4374-4388.

80. B. Zhang, X. Zhao, Y. Li and B. Hou, RSC Adv., 2016, 6, 35455-35465.

81. C.-H. Xue, X.-J. Guo, M.-M. Zhang, J.-Z. Ma and S.-T. Jia, J. Mater. Chem. A, 2015, 3, 21797-21804. 